\title{
High intensity focused ultrasound atrial fibrillation ablation during concomitant open heart surgery: is it time to offer this procedure to any patient undergoing cardiac surgery?
}

Volume 9 Issue 4 - 2017

\section{Editorial}

Atrial fibrillation (AF) is known to be an important risk factor for morbidity and mortality in open heart surgery. ${ }^{1}$ A $24 \%$ reduction in long-term survival has been described in patients undergoing coronary bypass surgery without conversion of atrial fibrillation into sinus rhythm. ${ }^{2}$ Not treated preoperative atrial fibrillation was also associated with increased late cardiac morbidity and mortality, and poor long-term survival. ${ }^{3-5}$ Surgical conventional atrial lesions are generally created under cardiopulmonary bypass after opening the left atrium with the utilization of different energy sources. ${ }^{6-10}$ The surgically performed ablation lines done with radiofrequency, microwave, or laser energy sources were designed to closely replicate the original lesion set described by James L. Cox for a successful treatment of AF, but without the operative time and morbid cost of the classic cut and sew Maze procedure. ${ }^{11}$ Indeed, due to the complexity of the Cox maze procedure, several different modifications have been introduced in an effort to simplify and shorten the operation. In addition, a left atriotomy performed in patients undergoing open heart surgery will increase cardiopulmonary bypass and cardiac exclusion times, as well as, morbidity and mortality. Therefore, any ablation technique that can be done before the initiation of cardiopulmonary bypass and without the necessity to perform a left atriotomy is a valid surgical alternative..$^{12}$ Indeed, a less-invasive epicardial AF ablation applied on the beating heart is definitely an attractive approach. ${ }^{13}$

In this issue of the Journal of Cardiology and Current Research, Romero-Ferrer B et al., ${ }^{14}$ evaluated the effectiveness and safety of pulmonary veins epicardial ablation in AF patients during open heart surgery. They divided their patients into two groups, one with 20 patients with paroxysmal AF and another with 39 chronic AF. The primary endpoint was the presence of sinus rhythm at one year of follow-up. The effectiveness of the procedure to maintain sinus rhythm was $67.8 \%$ at the end of surgery, $54.4 \%$ at discharge, 54.7 at one month, $62 \%$ at six months and $65.3 \%$ at one year. No significant differences were found according to the underlying disease or the type of $\mathrm{AF}$, although the results were better when AF was paroxysmal. There were no technique-related serious complications. ${ }^{14}$ The authors concluded that epicardial surgical ablation of the pulmonary veins with high-intensity focused ultrasounds is safe and shows good results, especially in patients with paroxysmal $\mathrm{AF}$, regardless of their underlying heart disease, and it should be offered when there is a surgical indication for their cardiac illness. ${ }^{14}$

Several clinical studies analyzed the success rates of maintainig sinus rhythm of this procedure utilizing devices using high-intensity focused ultrasounds. The detected success rates ranged from $65 \%$ to $90 \%$ using this energy source. ${ }^{12}$ In their study, Romero-Ferrer B et al., ${ }^{14}$ observed that $65.3 \%$ of their patients were in sinus rhythm

\author{
Osmar Antonio Centurión, ${ }^{1,2}$ Karina E \\ Scavenius, ${ }^{2}$ Luis M Miño, ${ }^{2}$ Orlando R \\ Sequeira ${ }^{2}$ \\ 'Department of Health Sciences's Investigation, Sanatorio \\ Metropolitano, Fernando de la Mora, Paraguay \\ ${ }^{2}$ Division of Cardiovascular Medicine, Clinic Hospital,Asunción \\ National University, San Lorenzo, Paraguay
}

\begin{abstract}
Correspondence: Osmar Antonio Centurion, Professor of Medicine, Asuncion National University, Department of Health Sciences $\square$ s Investigation, Sanatorio Metropolitano, Teniente Ettiene $215 \mathrm{c} /$ Ruta Mariscal Estigarribia, Fernando de la Mora, Paraguay, Email osmarcenturion@hotmail.com
\end{abstract}

Received: July 27, 2017 | Published: August 24, 2017

at one year of follow-up. Their results are in accord with previous studies. Schopka $\mathrm{S}$ et al., ${ }^{15}$ reports $62 \%$ maintenance of sinus rhythm at 6 and 12 months of follow-up. They studied 110 patients with AF and concomitant open heart surgery. Main underlying heart diseases were aortic valve disease $(50 \%)$, ischemic heart disease $(48 \%)$, and mitral valve disease (18\%). AF was paroxysmal in $29 \%$, persistent in $31 \%$, and long standing persistent in $40 \%$ of patients. All patients had successful application of the system on the beating heart prior to initiation of extracorporeal circulation. No device-related deaths occurred, and postoperative pacemaker insertion was necessary in 4 patients. Groh MA et al., ${ }^{16}$ studied 98 consecutive patients with a primary diagnosis of ischemic heart disease who underwent surgical therapy of atrial fibrillation concomitant to coronary bypass grafting using also epicardial ultrasound technology. Coronary artery bypass grafting was isolated or associated with various combinations of aortic, mitral, tricuspid, and left ventricular restoration surgery. At 12 month of follow-up, there were 1 early death and 4 extracardiac late deaths. A pacemaker was implanted in 4 patients. Freedom from atrial fibrillation at the 6 -month visit was $84 \%$ for the entire population, $76 \%$ in patients with permanent $\mathrm{AF}$, and $91 \%$ in patients with paroxysmal AF. At 1-year visit, $85 \%$ were free from atrial fibrillation. Camm $\mathrm{CF}$ et al., ${ }^{17}$ published a review of the most important articles in the literature with a sinus rhythm maintenance ranging from 60 to $82 \%$ after surgery and ablation procedure. Ninet $\mathrm{J}$ et al., ${ }^{12}$ reported sinus rhythm maintenance of $85 \%$ of patients at 6 months follow-up, and $100 \%$ when AF was paroxysmal. No complications or deaths were device or procedure related. There were $4(3.8 \%)$ early deaths and 2 late extracardiac deaths. A pacemaker was implanted in 8 patients. 
Similar results were achieved by different studies with this surgical AF ablation procedure. The goal of these technique is to create lines of intra-atrial conduction block that will preclude the development of reentrant rhythms in the atria, as well as, to isolate the triggers for AF development near the pulmonary veins to resume and maintain sinus rhythm. Structural and electrophysiological changes take place over time within the left atrial myocardium in patients with structural heart disease associated with AF. Over the years the atrial wall undergoes changes due to pressure and volume overload. The structural changes are due to dilatation of the atrium, to some degree of hypertrophy, fibrosis, and overstretching of the myocardial fibers. ${ }^{18}$ These changes produce an anatomical substrate with electrophysiological alterations which increases the likelihood of developing AF by causing heterogeneity in intraatrial and interatrial conduction. ${ }^{19,20}$ This non-uniform anisotropic properties cause an irregular and fractionated propagation of the depolarization wave. ${ }^{21-23}$ Structural inhomogeneity or local differences in electrophysiological or ultra-structural properties are considered to play a major role in the initiation of reentrant circuits and atrial arrhythmias due to the increased likelihood of unidirectional block of the premature impulse and conduction delay. ${ }^{24-26}$ Therefore, the mere isolation of triggers around the pulmonary veins will not be sufficient to suppress all causes and effects of $\mathrm{AF}$, since the arrhythmogenic foci known to trigger $\mathrm{AF}$ are more likely to reside in the left atrial myocardium than in the pulmonary veins in certain cases. ${ }^{20}$

Patients with paroxysmal AF showed a significantly higher success rate than those with persistent or long standing persistent AF. These patients with paroxysmal AF usually suffer from less pathologic alterations of the atrial myocardium including myocyte size, wall thickness, fibrotic changes and left atrial size. Nevertheless, there is a possibility that these good outcomes may have been a result of inadequate diagnostic measures to detect short periods of AF during follow-up, since some studies did not perform Holter ECG assessment, or implantation of event loop recorders in patients who underwent epicardial AF ablation. Romero-Ferrer B et al., ${ }^{14}$ also followed the heart rhythm of their ablated patients with conventional surface electrocardiograms only. Therefore, it is possible that the incidence of patients in sinus rhythm may have been overestimated. ${ }^{14}$

\section{Conclusion}

In conclusion, AF epicardial ablation concomitant to cardiac surgery appears to be an efficient procedure to improve outcome. Epicardial surgical ablation of the pulmonary veins with high intensity focused ultrasound is safe and demonstrated good results at one year of follow-up. It may be offered to patients with surgical indication for their underlying cardiac condition in association with paroxysmal AF. Despite these good results, it is not time yet to offer this procedure to any AF patient undergoing open heart surgery unless this efficacy is unequivocally proven in large randomized clinical trials.

\section{Acknowledgments}

None.

\section{Conflicts of interest}

Author declares there no conflicts of interest.

\section{Funding}

None.

\section{References}

1. Sergeant P, Blackstone EH, Meyns B. Validation and interdependence with patient-variables of the influence of procedural variables on early and late survival after CABG. Eur J Cardiothoracic Surg. 1997;12(1):1-19.

2. Quader MA, Mc Carthy PM, Gillinov AM, et al. Does preoperative atrial fibrillation reduce survival after coronary artery bypass grafting? Ann Thorac Surg. 2004;77(5):1514-1522.

3. Ngaage DL, Schaff HV, Mullany CJ, et al. Does preoperative atrial fibrillation influence early and late outcomes of coronary artery bypass grafting? J Thorac Cardiovasc Surg. 2007;133(1):182-189.

4. Roshanali F, Mandegar MH, Yousefnia MA, et al. Prediction of atrial fibrillation via atrial electromechanical interval after coronary artery bypass grafting. Circulation. 2007;116:2012-2017.

5. Ferguson TB , Hammill BG, Peterson ED, et al. A decade of changerisk profiles and outcomes for isolated coronary artery bypass grafting procedures, 1990-1999: a report from the STS National Database Committee and the Duke Clinical Research Institute. Ann Thorac Surg. 2002;73(2):480-489.

6. Benussi S, Nascimbene S, Agricola E, et al. Surgical ablation of atrial fibrillation using the epicardial radiofrequency approach: mid-term results and risk analysis. Ann Thorac Surg. 2002;74(4):1050-1057.

7. Knaut M, Tugtekin SM, Jung F, et al. Microwave ablation for the surgical treatment of permanent atrial fibrillation-a single centre experience. Eur J Cardiothorac Surg. 2004;26(4):742-746.

8. Williams MR, Casher JM, Russo MJ, et al. Laser energy source in surgical atrial fibrillation ablation: preclinical experience. Ann Thorac Surg. 2006;82(6):2260-2264.

9. Gaynor SL, Diodato MD, Prasad SM, et al. A prospective, single-center clinical trial of a modified Cox maze procedure with bipolar radiofrequency ablation. J Thorac Cardiovasc Surg. 2004;128(4):535-542.

10. Gillinov AM, Mc Carthy PM, Blackstone EH, et al. surgical ablation of atrial fibrillation with bipolar radiofrequency as the primary modality. $J$ Thorac Cardiovasc Surg. 2005;129(6):129:1322-1329.

11. Cox JL. The surgical treatment of atrial fibrillation: IV. Surgical technique. J Thorac Cardiovasc Surg. 1991;101(4):584-592.

12. Ninet $J$, Roques $X$, Seitelberger R, et al. surgical ablation of atrial fibrillation with off-pump, epicardial, high-intensity focused ultrasound: results of a multicenter trial. J Thorac Cardiovasc Surg. 2005;130(3):803-809.

13. Akpinar B, Sanisoglu I, Guden M, et al. Combined Off-Pump coronary artery bypass grafting surgery and ablative therapy for atrial fibrillation: early and mid-term results. Ann Thorac Surg. 2006;81(4):1332-1337.

14. Bernardo Romero-Ferrer, Josep Lupón, Irma Casas-García, et al. Pulmonary veins epicardial isolation with high-intensity focused ultrasounds for the treatment of non-primary atrial fibrillation. $J$ Cardiol Curr Res. 2011;9(4):00329.

15. Schopka S, Schmid C, Keyser A, et al. Ablation of atrial fibrillation with the Epicor system: a prospective observational trial to evaluate safety and efficacy and predictors of success. J Cardiothorac Surg. 2010;5:3439.

16. Groh MA, Binns OA, Burton HG, et al. Ultrasonic cardiac ablation for atrial fibrillation during concomitant cardiac surgery: long-term clinical outcomes. Ann Thorac Surg. 2007;84(6):1978-1983.

17. Camm CF, Nagendran M, Xiu PY, et al. How effective is cryoablation for atrial fibrillation during concomitant cardiac surgery? Interact Cardiovasc Thorac Surg. 2011; 13(4):410-414.

18. Abhayaratna WP1, Seward JB, Appleton CP, et al. Left atrial size: physiologic determinants and clinical applications. J Am Coll Cardiol. 2006;47(12):2357-2363 
19. Everett TH 4th, Wilson EE, Verheule S, et al. Structural atrial remodeling alters the substrate and spatio-temporal organization of atrial fibrillation: a comparison in canine models of structural and electrical atrial remodeling. Am J Physiol Heart Circ Physiol . 2006;291(6):H2911H2923.

20. Allessie M, Ausma J, Schotten U. Electrical, contractile and structural remodeling during atrial fibrillation. Cardiovasc Res. 2002;54(2):230-246.

21. Centurión OA, Shimizu A, Isomoto S, et al. Mechanisms for the genesis of paroxysmal atrial fibrillation in the Wolff- Parkinson-White syndrome: Intrinsic atrial muscle vulnerability vs. electrophysiological properties of the accessory pathway. Europace . 2008;10(3):294-302.

22. Spach MS, Miller WT 3rd, Dolber PC, et al. The functional role of structural complexities in the propagation of depolarization in the atrium of the dog. Cardiac conduction disturbances due to discontinuities of effective axial resistivity. Circ Res. 1982;50(2):175-191.
23. Centurión OA, Isomoto $\mathrm{S}$, Shimizu A, et al. The effects of aging on atrial endocardial electrograms in patients with paroxysmal atrial fibrillation. Clin Cardiol. 2003;26(9):435-438.

24. Centurión OA, Shimizu A, Isomoto S, et al. Influence of advancing age on fractionated right atrial endocardial electrograms. Am J Cardiol. 2005;96(2):239-242.

25. Centurión OA. Age-Related Electrophysiological Changes of the Atrial Myocardium in Patients with Paroxysmal Atrial Fibrillation. J Cardiol Curr Res. 2015;3(6):1-5.

26. Centurion OA, Isomoto S, Fukatani M, et al. Relationship between atrial conduction defects and fractionated atrial endocardial electrograms in patients with sick sinus syndrome. Pacing Clin Electrophysiol. 1993;16(10):2022-2033. 